\title{
Identifying complications of interventional procedures from UK routine healthcare databases: a systematic search for methods using clinical codes
}

Kim Keltie ${ }^{1,2}$, Helen Cole ${ }^{1}$, Mick Arber ${ }^{3}$, Hannah Patrick ${ }^{4}$, John Powell ${ }^{4}$, Bruce Campbell ${ }^{4}$ and Andrew Sims $s^{1,2^{*}}$

\begin{abstract}
Background: Several authors have developed and applied methods to routine data sets to identify the nature and rate of complications following interventional procedures. But, to date, there has been no systematic search for such methods. The objective of this article was to find, classify and appraise published methods, based on analysis of clinical codes, which used routine healthcare databases in a United Kingdom setting to identify complications resulting from interventional procedures.
\end{abstract}

Methods: A literature search strategy was developed to identify published studies that referred, in the title or abstract, to the name or acronym of a known routine healthcare database and to complications from procedures or devices. The following data sources were searched in February and March 2013: Cochrane Methods Register, Conference Proceedings Citation Index - Science, Econlit, EMBASE, Health Management Information Consortium, Health Technology Assessment database, MathSciNet, MEDLINE, MEDLINE in-process, OAlster, OpenGrey, Science Citation Index Expanded and ScienceDirect. Of the eligible papers, those which reported methods using clinical coding were classified and summarised in tabular form using the following headings: routine healthcare database; medical speciality; method for identifying complications; length of follow-up; method of recording comorbidity. The benefits and limitations of each approach were assessed.

Results: From 3688 papers identified from the literature search, 44 reported the use of clinical codes to identify complications, from which four distinct methods were identified: 1) searching the index admission for specified clinical codes, 2) searching a sequence of admissions for specified clinical codes, 3) searching for specified clinical codes for complications from procedures and devices within the International Classification of Diseases $10^{\text {th }}$ revision (ICD-10) coding scheme which is the methodology recommended by NHS Classification Service, and 4) conducting manual clinical review of diagnostic and procedure codes.

Conclusions: The four distinct methods identifying complication from codified data offer great potential in generating new evidence on the quality and safety of new procedures using routine data. However the most robust method, using the methodology recommended by the NHS Classification Service, was the least frequently used, highlighting that much valuable observational data is being ignored.

Keywords: Adverse effects, Medical errors, Patient safety, Health information systems

\footnotetext{
*Correspondence: andrew.sims@nuth.nhs.uk

'Newcastle upon Tyne Hospitals NHS Foundation Trust, Newcastle Upon

Tyne, UK

${ }^{2}$ Institute of Cellular Medicine, Newcastle University, UK

Full list of author information is available at the end of the article
} 


\section{Background}

Complications are an important consideration in assessing the safety and efficacy of new interventional procedures $[1,2]$, but reliable data are difficult to acquire. Complications of interventional procedures may relate to the procedures themselves, devices used to conduct the procedure, or to implanted devices. In recent times, the complications of devices have become a particular concern, with the high profile examples of breast implants [3] and metal-on-metal hip implants [4].

For assessing effectiveness in clinical practice, observational research can complement evidence from randomised controlled trials, by identifying the nature and frequency of adverse events [5] and detecting rare outcomes [6-8]. For interventional procedures, a common approach is to establish a dedicated clinical register to capture information about diseases, procedures and devices in selected study populations [9], but there can be many obstacles to establishing dedicated registers and submission to them may be incomplete [10]. An alternative is to use routine healthcare databases [11] that capture information from large populations across a broad range of interventions. Such data are available more readily and at a lower cost than bespoke patient registers $[12,13]$ and have been used to assess outcomes of interventional procedures in clinical practice $[14,15]$.

Several authors have developed and applied methods to routine data sets to identify the nature and rate of complications following interventional procedures. But, to date, there has been no systematic search of such methods. The aim of this study was to find, classify and appraise published methods which used routine healthcare databases to identify complications from interventional procedures, in a United Kingdom (UK) setting. This paper considers methods based on analysis of clinical codes.

\section{Methods}

This study was based on a systematic search of scientific literature and did not involve primary research with human subjects, human material or human data; no ethical approval was required.

\section{Data sources}

The following databases were searched: Cochrane Methodology Register, Conference Proceedings Citation Index - Science, Econlit, EMBASE, Health Management Information Consortium, Health Technology Assessment database, MathSciNet, MEDLINE, MEDLINE in-process, OAIster, OpenGrey, Science Citation Index Expanded and ScienceDirect. Where database functionality allowed, searches were limited to results published from 1987 and in English language. Searches were carried out in February and March 2013. The MEDLINE search strategy is described in Additional file 1. This was adapted as appropriate for each database searched.

\section{Study selection}

Six healthcare databases used in the UK, identified from an initial scoping search, were considered in this study. Two were routine administrative databases used to record episodes of patient care in the UK National Health Service (NHS): Hospital Episode Statistics (HES) [16] and the Clinical Practice Research Datalink (CPRD) [17]. Two were databases used to record deaths: the Office for National Statistics (ONS) database [18] and the Primary Care Mortality Database (PCMD) [19]. The remaining two were adverse incident databases: the National Reporting and Learning System (NRLS) [20] and the Medicines and Healthcare products Regulatory Agency (MHRA) database of adverse drug reactions, defective medicines, device failures and blood product safety reports. Synonymous and related terms for these data sources included the General Practice Research Database (GPRD) (former name for CPRD), the National Patient Safety Agency (NPSA) which operated the NRLS, and Datix ${ }^{\mathrm{Tx}}$, a commercial product used by many hospitals to manage incidents and which provides summary reports to NRLS.

Papers reporting primary or secondary research with a clearly defined methodology were included if they described the use of at least one of the data sources included in the scope with the intention of identifying complications from procedures or devices. Exclusion criteria were: non-English language studies, conference abstracts, studies published before 1987 (when both HES and GPRD administrative databases were established) and studies with methods not considered repeatable from the description provided.

Titles and abstracts of the literature search results were independently reviewed by two authors (KK and $\mathrm{HC}$ ) and arbitrated by a third (AS). When a paper could not be ruled out from the information available in the title and abstract, the full paper was retrieved. Two authors (KK and $\mathrm{HC}$ ), arbitrated by a third (AS), independently reviewed the full papers and applied the eligibility criteria to each. Studies from eligible papers were inductively classified (KK and AS arbitrated by HC) into different methods of identifying complications; each method being a combination of type of database and whether direct clinical coding of complications or surrogate indicators of complications were used. Of the eligible papers, those which reported methods using clinical coding were reviewed, and data extracted using a standard template.

\section{Results and discussion Eligible papers}

In total, 3688 records were assessed for relevance by two authors (arbitration by a third was required for 43 papers, 
1.2\%); 3180 were subsequently excluded using information from the title and abstract. Full text articles were retrieved for the remaining 508 records. Of these, 408 did not meet the eligibility criteria, leaving 100 full articles for further analysis (Figure 1). Forty-four articles reported the identification of complications using methods based on clinical codes $(59.1 \%$ of which also used surrogate measures to identify complications) and were included in this study (a summary of which is included in Additional file 2). The remaining sixty-six articles were excluded on the basis of using only surrogate measures to identify complications.

\section{Characteristics of eligible studies}

Table 1 shows the distribution of studies by medical specialty and routine healthcare database. The clinical coding schemes used in these databases were the International Classification of Diseases (ICD) [22], the Office of Population Census and Surveys Classifications of Interventions and Procedures (OPCS) [23] and READ [24] codes.

Thirty-seven articles (94.1\%) included a period of followup which extended beyond the duration of the initial (i.e. index) admission; this ranged from 2 days to 23 years in the studies found. Twenty papers captured co-morbidities for each patient; 13 used the Charlson comorbidity index [25], 5 recorded only specified comorbidities and 2 used the modified Royal College of Surgeons Charlson comorbidity index [26]. Socioeconomic deprivation was captured
Table 1 Distribution of eligible studies by medical specialty and routine healthcare database

\begin{tabular}{|c|c|c|c|c|}
\hline \multirow[t]{2}{*}{ Medical specialty } & \multicolumn{3}{|c|}{ Routine healthcare database } & \multirow{2}{*}{$\begin{array}{l}\text { Total } \\
\text { no. of } \\
\text { papers }\end{array}$} \\
\hline & HES & CPRD & $\mathrm{SMR}^{\dagger}$ & \\
\hline Gastro-intestinal & 16 & 1 & & 17 \\
\hline Orthopaedic & 9 & & & 9 \\
\hline Vascular & 5 & & & 5 \\
\hline All medical specialties & 3 & & & 3 \\
\hline Urology & 3 & & & 3 \\
\hline Obstetrics \& gynaecology & 2 & & 1 & 3 \\
\hline Respiratory & 3 & & & 3 \\
\hline Radiology & & 1 & & 1 \\
\hline Total studies & 41 & 2 & 1 & \\
\hline
\end{tabular}

${ }^{\dagger}$ Indicates a database which was not included within literature search terms but was detected incidentally from review of full articles.

in 9 studies; 8 used the Carstairs Index of Deprivation [27] and one used the Index of Multiple Deprivation, 2004 [28].

Four distinct methodological approaches (referred to hereafter as approaches (a-d)) based on clinical coding were found during inductive classification of the fortyfour articles, these identified complications by: a) searching the index admission for specified clinical codes, b) searching a sequence of admissions for specified clinical

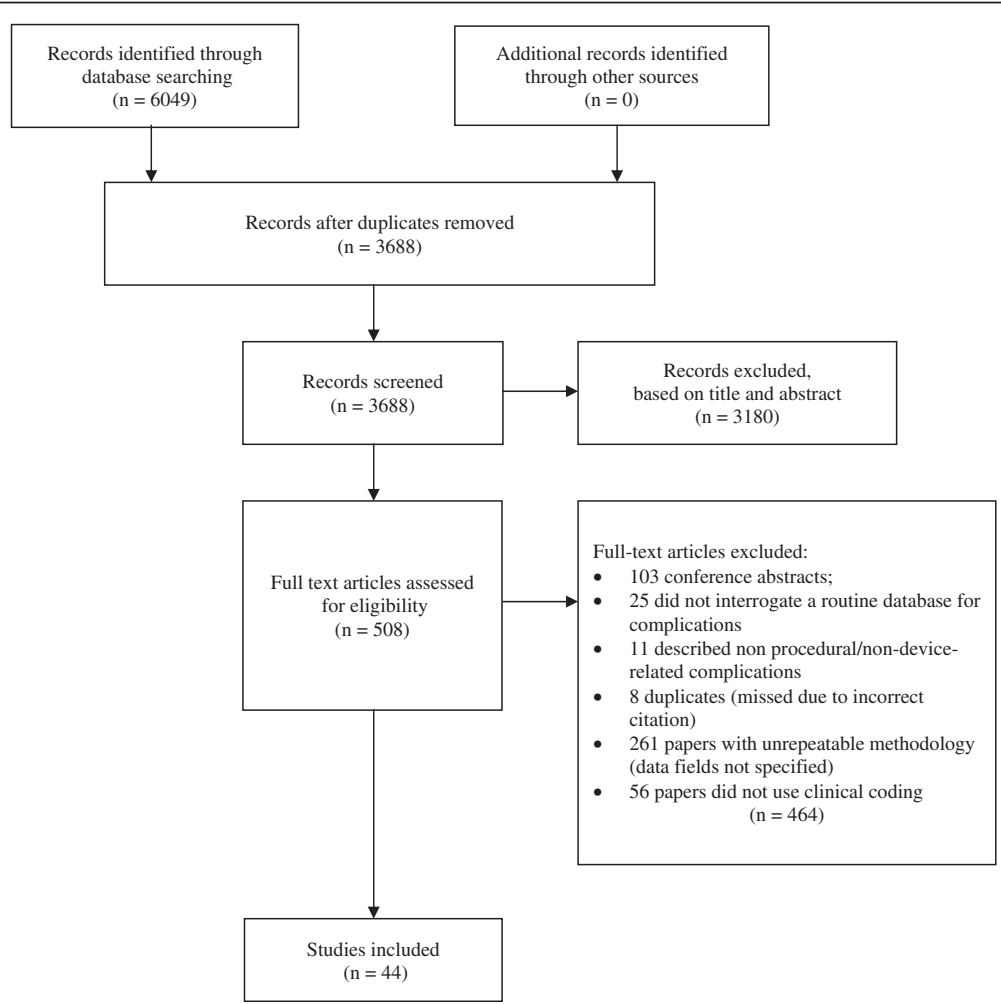

Figure 1 Flow of information through different phases of the study [21]. 
codes, c) applying the methodology recommended by NHS Classification Service, and d) conducting manual clinical review of diagnostic and procedure codes.

\section{Complications identified by searching the index admission for specified clinical codes (a)}

In 13 papers, the authors began by listing codes for potential peri-procedural complications or emergency corrective procedures and then searched for them in the index admission only [29-41]. All used the HES database in which procedures are coded using the Office of Population Censuses and Surveys Classification of Interventions and Procedures (OPCS-4) system and diagnoses are coded using the International Classification of Diseases 10th revision (ICD-10) system.

Ten of these studies searched for diagnostic codes [30-32,34-40]. Of these, six [30-32,37,39,40] included clinical codes specifically intended for recording complications. These were the ICD-10 diagnosis codes from the range T80-T88 ("complications of surgical and medical care, not elsewhere classified"), or equivalent values from earlier versions of ICD classification. For example, El-Dhuwaib et al. [31] compared outcomes of laparoscopic versus open repair of inguinal hernia, and searched for the presence of, amongst others, code T81.2 ("accidental puncture and laceration during a procedure, not elsewhere classified"), to indicate the occurrence of a procedural complication. However, some studies used unqualified disease codes to indicate a complication [30-32,34,39,40]. For example, Holt et al. [39] counted the presence of ICD-10 code I63 ("cerebral infarction") as a complication of aortic aneurysm repair.

Only two studies restricted their use of diagnostic codes to those specifically intended for recording complications $[32,34]$ to overcome the difficulty of discriminating between complications and co-morbidities. For example, the Department of Health searched for a specific complication code related to wound site infection for all types of admission in England over one year [32].

Eight of the 13 studies [29,30,32-35,38,41] considered the occurrence of certain additional procedures during the index admission to indicate a complication. For example, Almoudaris et al. [29] studied colorectal cancer resections and the frequency of reoperations (including washout of abdomen and drainage of abscesses). Three studies $[30,34,38]$ used a combination of specific diagnoses and additional procedures to identify complications. For example, Onwere et al. [34] captured, with high sensitivity, incidences of blood transfusion associated with caesarean section deliveries in women with placenta praevia through the presence of particular OPCS-4 codes and ICD-10 diagnosis codes.

\section{Complications identified by searching a sequence of admissions for specified clinical codes (b)}

In an extension of the technique described above (a), the authors of 35 papers listed codes for potential complications and emergency corrective procedures and then searched for them in a sequence of admissions. Thirtythree of these used HES and two used CPRD. Subsequent admissions were used to identify complications from the index admission that became apparent after discharge.

Twenty-one of the 35 papers in this category searched readmission records [29,31,32,42-59], with follow-up intervals that ranged from within 2 days [31] to 13 years [58]. For example, Kulkarni et al. [52] identified postoperative complications of total hip and knee replacement in patients who also had bariatric surgery by searching for medical complications, such as myocardial infarction, occurring within 30 days of surgery, deep vein thrombosis or pulmonary embolism within 90 days, hip revisions within 12 months, or dislocations within 18 months.

Ten of the 35 papers searched both the index admission and readmissions [30,36,60-67]. For example, Hilton \& Cromwell [61] estimated rates of fistula in hysterectomy patients by searching for specific diagnostic codes within the index admission and readmissions within 12 months.

The remaining four papers of the 35 in this category searched admissions before, during and after the index admission [68-71]. Admissions before the index admission were used to help identify co-morbidities and to distinguish them from complications. For example, Mamidanna et al. [70] identified medical complications of emergency colorectal surgery in the elderly by capturing specified diagnoses (e.g. angina, atrial fibrillation) during the index admission or in readmissions within 30 days, only if they were not recorded during previous admissions in the five years preceding surgery. A similar, but alternative approach was adopted by Smith et al. [71], who used HES to determine whether there was an increased risk of cancer in the early years after metalon-metal hip replacement due to biological effects of the metals.

\section{Complications identified using the methodology recommended by NHS Classification Service (c)}

The ICD-10 coding scheme includes provision for the clinical coding of complications from procedures and devices. There are also disease codes which indicate a complication in their own right (e.g. 197 - "post-procedural disorders of the circulatory system, not elsewhere classified") and there are codes which can be used to qualify other diseases as being iatrogenic. For example, if code Y83 ("surgical operation and other surgical procedures as the cause of abnormal reaction of a patient, or of later complication, without a mention of misadventure at the 
time of the procedure") followed, or qualified, code I63 ("cerebral infarction"), it would indicate that the stroke was the result of a procedure.

Only one paper made full use of this convention to identify adverse events. Aylin et al. [72] searched HES for the presence of 41 different ICD-10 three character codes, including codes for iatrogenic disease and qualifying codes, specifically intended to identify the frequency of 'adverse events' and 'medical or surgical misadventure'. They applied this technique to HES records of all inpatient admissions in NHS in England between 1999 and 2003, and estimated that, on average, $2.2 \%$ of all episodes include a code for an adverse event, and $0.03 \%$ for a misadventure.

\section{Complications identified by manual clinical review of diagnostic and procedure codes (d)}

Manual clinical review of HES records was reported in three papers $[53,56,66]$. For example, Cathcart et al. [56] manually examined all diagnostic and procedure codes for circumcisions, when the length of stay exceeded one day or when a patient was readmitted within 30 days.

\section{Conclusions}

\section{Statement of principal findings}

The aim of this study was to find, classify and appraise published methods based on the analysis of clinical codes from routine healthcare databases in a UK setting to identify complications from interventional procedures. Four distinct methods of identifying complications were found, and to our knowledge, this is the first search and classification of published methods for identifying complications from routine data.

Coding schemes provide a compact, structured and logically consistent scheme for representing complex clinical records. They provide the basis for the development of algorithms to identify procedures, diseases and events of interest. Several authors have applied algorithms to large codified data sets, such HES, to identify complication rates at national level for procedures of interest, but each of these approaches has limitations in overcoming particular challenges. For example, searching only for a prospective list of diagnoses (deemed as complications) may lead to underestimation of the true peri-procedural complication rate if complications were not anticipated from earlier trial outcomes or expert opinion. Additionally, diagnosis codes (e.g. I63 - "cerebral infarction") are used to code both comorbidities and complications, and therefore searching for them in isolation may overestimate the peri-procedural complication rate. Manual review of codified data by clinical experts, in the absence of patient notes, is a very time-consuming and impractical alternative approach which does not overcome either of these limitations and it may also be subject to operator error or observer bias.

Using the presence of multiple procedure codes occurring within the same hospital admission as a marker of procedural complication may also be misleading because there are many reasons why additional procedures may be necessary. Without clinical review or access to case notes, additional procedures cannot be confidently used as a surrogate for complications. In addition, searching only for a prospective list of possible repair procedures may miss complications that were resolved by other means and may lead to an underestimation of the true complication rate.

HES data have been used most frequently for assessing short-term complications (typically those arising periprocedurally and within 30 days). Their utility for identifying longer-term complications remains uncertain for two main reasons. Firstly, the process of constructing comprehensive longitudinal patient records from multiple data sources (e.g. primary and secondary care) is complex and laborious. Secondly, over extended periods of time, the certainty with which adverse outcomes can be attributed to particular procedures is reduced. None of the eligible studies that considered longer-term outcomes has fully overcome these limitations.

Only one paper included in our study used the facility implicit within the ICD-10 coding scheme to identify short-term complications. This method, which is based on the use of supplementary codes to indicate complication and specific codes for iatrogenic disease, overcomes the problem of separating complications from co-morbidities and avoids the need to use the incidence of additional procedures as a surrogate marker of complication. It is surprising that it has been applied so rarely to date.

\section{Strengths and weaknesses of the study}

This study was based on a systematic search for published studies that identified complications from specific routine data sources using analysis of clinical codes. Because the search found so many eligible studies, we were able to group together methods which had been applied to diverse clinical disciplines and appraise the strengths, limitations and clinical utility of each.

Although the study was limited to routine databases used in the United Kingdom, the identified methods are more widely applicable. Methods using the international standard, ICD-10, for coding diseases are directly applicable to other healthcare settings and an increasing number of countries are using ICD for the purposes of reimbursement and healthcare resource allocation [22]. 
For example, Quan et al. recently surveyed 31 countries, all of which use ICD coding systems, and found that 24 (77.4\%) specifically used ICD-10 [73]. OPCS and READ coding schemes are specific to the UK setting, but the strengths and weaknesses of the methods that used these schemes for identifying complications are applicable to any databases using codified clinical terms.

Because the scope was intentionally non-specific to a particular clinical context the search strategy was designed to find studies which included non-specific complication related index and free text terms. Studies that used specific terms to describe complications would not necessarily have been retrieved but may have included generalizable methods which were not otherwise captured.

\section{Meaning of the study: possible implications for clinicians and policymakers}

The ICD-10 scheme includes provision for the clinical coding of complications and adverse incidents. Using codes in the ranges T80-88 and Y40-84 to distinguish comorbidities from complications is recommended strategy for the NHS [74]. However, few studies to date have taken full advantage of the capabilities of ICD-10 for this purpose. But why has that been the case? It may be speculated that full exploitation of these codes requires relatively sophisticated manipulation of code sequences at episode-level (for example to group a main disease code with a qualifying Y-code immediately following it) and that these techniques have not been readily available to most researchers.

The next version of the International Classification of Diseases, ICD-11 [75], will include an extensive revision of ICD-10 chapters 19 and 20 which are concerned with healthcare related injury. ICD-11 will provide a mechanism to encode the cause of harm, the mode or mechanism of harm and the harm incurred. Specific consideration is also being given to the number of diagnosis fields needed to capture safety events [76], improved methods for recording morbidity and for reporting the timing of diagnoses [73].

The improvements proposed for ICD-11 are an important development for clinicians, clinical coders and researchers, but our study has shown that information about healthcare related injury, already recorded in health records using ICD-10, remains largely unexploited. Important evidence that would likely change current practice is being ignored and more should be done to use it for patient benefit.

\section{Unanswered questions and further research}

Further research is needed into the utility of clinical codes used to indicate iatrogenic disease. In particular there is a need to develop algorithms that exploit the use of such codes and to validate these algorithms using corroborative datasets, such as bespoke clinical registers or local patient records.

Complications with longer term manifestations require data linkage with mortality records, incident databases and other routine national databases in order to provide a longitudinal patient record, but there is a need for the development and assessment of new methods, based on such data linkage, to capture longer-term events and consequences reliably.

\section{Additional files}

Additional file 1: Literature search strategy. Literature search strategy terms.

Additional file 2: Summary of eligible studies describing methods of deriving complications using codified data from routine healthcare databases. Large (A3 landscape) table.

\section{Abbreviations}

CPRD: Clinical practice research datalink; FTR-S: Failure to rescue surgical; GPRD: General practice research database; HES: Hospital episode statistics; ICD: International classification of diseases; LoS: Length of stay;

MHRA: Medicines \& healthcare products regulatory agency; NHS: National health service; NPSA: National patient safety agency; NRLS: National reporting \& learning system; ONS: Office for national statistics; OPCS: Office of population censuses \& surveys classification of interventions \& procedures; PCMD: Primary care mortality database; UK: United Kingdom.

\section{Competing interests}

The authors declare that they have no competing interests.

\section{Authors' contributions}

KK participated in the design, reviewed abstracts and full papers, classified the studies and drafted the manuscript. HC reviewed abstracts and full papers. MA designed, reviewed and ran the literature search. HP conceived the study and participated in its design. JP and BC participated in the study design and proposed the manuscript structure. AJS participated in the design, reviewed full papers and helped draft the manuscript. All authors reviewed, edited and approved the final manuscript.

\section{Authors' information}

HP and JP are Consultant Clinical Advisers to the National Institute for Health and Care Excellence (NICE) Interventional Procedures Programme. BC is Chair of the NICE Interventional Procedures Advisory Committee and the NICE Medical Technologies Advisory Committee. KK, HC, and AS are employed by the Newcastle upon Tyne NHS Hospitals Foundation Trust and MA is employed by the York Health Economics Consortium, which are partner organisations that provide an External Assessment Centre to NICE.

\section{Acknowledgements}

This work was supported by the National Institute of Health and Care Excellence [Newcastle upon Tyne Hospitals NHS Foundation Trust and York Health Economics Consortium are partners in providing an External Assessment Centre to NICE].

\section{Author details}

${ }^{1}$ Newcastle upon Tyne Hospitals NHS Foundation Trust, Newcastle Upon Tyne, UK. ${ }^{2}$ Institute of Cellular Medicine, Newcastle University, UK. ${ }^{3}$ York Health Economics Consortium, York, UK. ${ }^{4}$ National Institute for Health and Care Excellence, London, UK.

Received: 19 March 2014 Accepted: 18 November 2014

Published: 28 November 2014 


\section{References}

1. Brennan TA, Leape LL, Laird NM, Hebert L, Localio AR, Lawthers AG, Newhouse JP, Weiler PC, Hiatt HH: Incidence of adverse events and negligence in hospitalized patients - results of the Harvard Medical Practice Study I. N Eng J Med 1991, 324:370-376.

2. Walshe K: Adverse events in health care: issues in measurement. Qual Health Care 2000, 9:47-52

3. Heneghan C: The saga of poly implant prosthèse breast implants. BMJ 2012, 344:e306.

4. Cohen D: How safe are metal-on-metal hip implants? BMJ 2012, 344:e1410.

5. Ho PM, Peterson PN, Masoudi FA: Evaluating the evidence: is there a rigid hierarchy? Circulation 2008, 118:1675-1684.

6. Hannan EL: Randomized clinical trials and observational studies: guidelines for assessing respective strengths and limitations. J Am Coll Cardiol Intv 2008, 1(3):211-217.

7. Jepsen P, Johnsen SP, Gillman MW, Sørensen HT: Interpretation of observational studies. Heart 2004, 90(8):956-960.

8. Thadhani R, Tonelli M: Cohort studies: marching forward. Clin J Am SoC Neph 2006, 1(5):1117-1123.

9. Gliklich RE, Dreyer NA: Registries for evaluating patient outcomes: a user's guide. 2nd edition. Edited by Gliklich RE, Dreyer NA. Rockville, MD: Agency for Health care Research and Quality (AHRQ); 2010.

10. Black N, Barker M, Payne M: Cross sectional survey of multicentre clinical databases in the United Kingdom. BMJ 2004, 328:1478-1482.

11. Hansell A, Bottle A, Shurlock L, Aylin P: Accessing and using hospital activity data. J Public Health Med 2001, 23:51-56.

12. Raftery J, Roderick P, Stevens A: Potential use of routine databases in health technology assessment. Health Technol Assess 2005, 9(20):1-92.

13. Patrick H, Sims A, Burn J, Bousfield D, Colechin E, Reay C, Alderson N, Goode S, Cunningham D, Campbell B: Monitoring the use and outcomes of new devices and procedures: how does coding affect what Hospital Episode Statistics contribute? Lessons from 12 emerging procedures 2006-10. J Publ Health 2013, 35(1):132-138

14. Aylin P, Bottle A, Majeed A: Use of administrative data or clinical databases as predictors of risk of death in hospital: comparison of models. BMJ 2007, 334:1044-1051.

15. Harrison EM, O'Neill S, Meurs TS, Wong PL, Duxbury M, Paterson-Brown S, Wigmore SJ, Garden OJ: Hospital volume and patient outcomes after cholecystectomy in Scotland: retrospective, national population based study. BMJ 2012, 344:e3330.

16. Health and Social Care Information Centre (HSCIC) (a), UK: Hospital Episode Statistics. http://www.hscic.gov.uk/hes.

17. Medicines and Healthcare Products Regulatory Agency (MHRA): Clinical Practice Research Datalink. http://www.cprd.com/intro.asp.

18. Office for National Statistics: http://www.ons.gov.uk.

19. Health and Social Care Information Centre (HSCIC) (b): Primary Care Mortality Database (PCMD). http://www.hscic.gov.uk/pcmdatabase.

20. NHS Commissioning Board (NCB): National Reporting and Learning System. https://report.nrls.nhs.uk/nrlsreporting/.

21. Moher D, Liberati A, Tetzlaff DG, Altman DG, The PRISMA Group: Preferred reporting items for systematic reviews and meta-analyses: the PRISMA statement. PLOS Med 2009, 6:e100097.

22. World Health Organisation (WHO): International Classification of Diseases (ICD). http://www.who.int/classifications/icd/factsheet/en/.

23. Health \& Social Care Information Centre (HSCIC): Office of Population Censuses and Surveys (OPCS) Classification of Surgical Operations and Procedures (4th revision). http//systems.hscic.gov.uk/data/clinicalcoding/codingstandards/opcs4.

24. Health \& Social Care Information Centre (HSCIC): READ codes. http://systems.hscic.gov.uk/data/uktc/readcodes.

25. Charlson ME, Pompei P, Ales KL, Mackenzie CR: A new method of classifying prognostic comorbidity in longitudinal studies: Development and validation. J Chron Dis 1987, 40:373-383.

26. Armitage $\mathrm{JN}$, van der Meulen $\mathrm{JH}$ : Identifying co-morbidity in surgical patients using administrative data with the Royal College of Surgeons Charlson Score. Br J Surg 2010, 97(5):772-781.

27. Carstairs V, Morris R: Deprivation: explaining differences in mortality between Scotland and England and Wales. BMJ 1989, 299:886-889.

28. Noble M, Wright G, Dibben C, Smith GAN, McLennan D, Anttila C, Barnes H, Mokhtar C, Noble S, Avenell D, Gardner J, Covizzi I, Lloyd M: Indices of Deprivation 2004. In Report to the Office of the Deputy Prime Minister. London: Neighbourhood Renewal Unit; 2004
29. Almoudaris AM, Burns EM, Bottle A, Aylin P, Darzi A, Vincent C, Faiz O: Single measures of performance do not reflect overall institutional quality in colorectal cancer surgery. Gut 2013, 62(3):423-429.

30. Burns EM, Currie A, Bottle A, Aylin P, Darzi A, Faiz O: Minimal-access colorectal surgery is associated with fewer adhesion-related admissions than open surgery. Br J Surg 2013, 100(1):152-159.

31. El-Dhuwaib Y, Corless D, Emmett C, Deakin M, Slavin J: Laparoscopic versus open repair of inguinal hernia: a longitudinal cohort study. Surg Endosc 2013, 27(3):936-945.

32. NHS Executive: Clinical indicators for the NHS (1994-95): a consultation document. 1997

33. Almoudaris AM, Burns EM, Mamidanna R, Bottle A, Aylin P, Vincent C, Faiz O Value of failure to rescue as a marker of the standard of care following reoperation for complications after colorectal resection. Br J Surg 2011, 98(12):1775-1783.

34. Onwere C, Gurol-Urganci I, Cromwell DA, Mahmood TA, Templeton A, van der Meulen $\mathrm{JH}$ : Maternal morbidity associated with placenta praevia among women who had elective caesarean section. Eur J Obstet Gynaecol Reprod Biol 2011, 159(1):62-66.

35. Ballal M, David G, Willmott S, Corless DJ, Deakin M, Slavin JP: Conversion after laparoscopic cholecystectomy in England. Surg Endosc 2009, 23(10):2338-2344.

36. David GG, Al-Sarira AA, Willmott S, Cade D, Corless DJ, Slavin JP: Use of Hartmann's procedure in England. Colorectal Dis 2009, 11(3):308-312.

37. Jen $M H$, Holmes $A H$, Bottle A, Aylin P: Descriptive study of selected healthcare-associated infections using national Hospital Episode Statistics data 1996-2006 and comparison with mandatory reporting systems. J Hosp Infect 2008, 70(4):321-327.

38. Raleigh VS, Cooper J, Bremner SA, Scobie S: Patient safety indicators for England from hospital administrative data: case-control analysis and comparison with US data. BMJ 2008, 337:a1702.

39. Holt PJ, Poloniecki JD, Loftus IM, Michaels JA, Thompson MM: Epidemiological study of the relationship between volume and outcome after abdominal aortic aneurysm surgery in the UK from 2000 to 2005. Br J Surg 2007, 94(4):441-448

40. Holt PJ, Poloniecki JD, Loftus IM, Thompson MM: The relationship between hospital case volume and outcome from carotid endartectomy in England from 2000 to 2005. Eur J Vasc Endovasc Surg 2007, 34(6):646-654.

41. Clark MP, Waddell A: The surgical arrest of post-tonsillectomy haemorrhage: hospital episode statistics. Ann R Coll Surg Engl 2004, 86(6):411-412.

42. Dyer J, Wyke S, Lynch C: Hospital Episode Statistics data analysis of postoperative venous thromboembolus in patients undergoing urological surgery: a review of 126,891 cases. Ann R Coll Surg Eng/ 2013, 95(1):65-69.

43. Amar RK, Jick SS, Rosenberg D, Maher TM, Meier CR: Drug-/radiation-induced interstitial lung disease in the United Kingdom general population: incidence, all-cause mortality and characteristics at diagnosis. Respirology 2012, 17(5):861-868

44. El-Dhuwaib Y, Deakin M, David GG, Durkin D, Corless DJ, Slavin JP: Definitive management of gallstone pancreatitis in England. Ann R Coll Surg Engl 2012, 94(6):402-406.

45. Jameson SS, Khan SK, Baker P, James P, Gray A, Reed MR, Deehan DJ: A national analysis of complications following hemiarthroplasty for hip fracture in older patients. QJM 2012, 105(5):455-460.

46. Lalmohamed A, de Vries F, Bazelier MT, Cooper A, van Staa TP, Cooper C, Harvey NC: Risk of fracture after bariatric surgery in the United Kingdom: population based, retrospective cohort study. BMJ 2012, 345:e5085.

47. Stafford GH, Charman SC, Borroff MJ, Newell C, Tucker JK: Total hip replacement for the treatment of acute femoral neck fractures: results from the National Joint Registry of England and Wales at 3-5 years after surgery. Ann R Coll Surg Engl 2012, 94(3):193-198.

48. Sutton PA, El-Dhuwaib Y, Dyer J, Guy AJ: The incidence of post operative venous thromboembolism in patients undergoing varicose vein surgery recorded in Hospital Episode Statistics. Ann R Coll Surg Engl 2012, 94(7):481-483

49. Burns EM, Bottle A, Aylin P, Clark SK, Tekkis PP, Darzi A, Nicholls RJ, Faiz O: Volume analysis of outcome following restorative proctocolectomy. $\mathrm{Br}$ Surg 2011, 98(3):408-417.

50. Cooper K, Lee A, Chien P, Raja E, Timmaraju V, Bhattacharya S: Outcomes following hysterectomy or endometrial ablation for heavy menstrual bleeding: retrospective analysis of hospital episode statistics in Scotland. BJOG 2011, 118(10):1171-1179. 
51. Kim K, Amonkar MM, Hogberg D, Kasteng F: Economic burden of resected squamous cell carcinoma of the head and neck in an incident cohort of patients in the UK. Head Neck Oncol 2011, 3:47.

52. Kulkarni A, Jameson SS, James P, Woodcock S, Muller S, Reed MR: Does bariatric surgery prior to lower limb joint replacement reduce complications? Surgeon 2011, 9(1):18-21.

53. West J, Card TR: Reduced mortality rates following elective percutaneous liver biopsies. Gastroenterology 2010, 139(4):1230-1237.

54. David GG, Al-Sarira AA, Willmott S, Deakin M, Corless DJ, Slavin JP: Management of acute gallbladder disease in England. Br J Surg 2008, 95(4):472-476.

55. Sibanda N, Copley LP, Lewsey JD, Borroff M, Gregg P, MacGregor AJ, Pickford M, Porter M, Tucker K, van der Meulen JH, on behalf of the Steering Committee of the National Joint Registry (NJR) for England and Wales: Revision rates after primary hip and knee replacement in England between 2003 and 2006. PLoS Med 2008, 5(9):e179.

56. Cathcart P, Nuttall M, van der Meulen J, Emberton M, Kenny SE: Trends in paediatric circumcision and its complications in England between 1997 and 2003. Br J Surg 2006, 93(7):885-890.

57. Judge A, Chard J, Learmonth I, Dieppe P: The effects of surgical volumes and training centre status on outcomes following total joint replacement: analysis of the Hospital Episode Statistics for England. J Publ Health 2006, 28(2):116-124.

58. Dixon T, Shaw M, Ebrahim S, Dieppe P: Trends in hip and knee joint replacement: socioeconomic inequalities and projections of need. Ann Rheum Dis 2004, 63(7):825-830.

59. Jameson SS, Jensen CD, Elson DW, Johnson A, Nachtsheim C, Rangan A, Muller SD, Reed MR: Cemented versus cementless hemiarthroplasty for intracapsular neck of femur fracture-A comparison of 60,848 matched patients using national data. Injury 2013, 44(6):730-734.

60. Sinha S, Hofman D, Stoker DL, Friend PJ, Poloniecki JD, Thompson MM, Holt PJ: Epidemiological study of provision of cholecystectomy in England from 2000 to 2009: retrospective analysis of Hospital Episode Statistics. Surg Endosc 2013, 27(1):162-175.

61. Hilton P, Cromwell DA: The risk of vesicovaginal and urethrovaginal fistula after hysterectomy performed in the English National Health Service-a retrospective cohort study examining patterns of care between 2000 and 2008. BJOG 2012, 119(12):1447-1454.

62. Moxey PW, Hofman D, Hinchliffe RJ, Poloniecki J, Loftus IM, Thompson MM, Holt PJ: Volume-outcome relationships in lower extremity arterial bypass surgery. Ann Surg 2012, 256(6):1102-1107.

63. Burns EM, Bottle A, Aylin P, Darzi A, Nicholls RJ, Faiz O: Variation in reoperation after colorectal surgery in England as an indicator of surgical performance: retrospective analysis of Hospital Episode Statistics. BMJ 2011, 343:d4836

64. Moxey PW, Hofman D, Hinchliffe RJ, Jones K, Thompson MM, Holt PJ: Trends and outcomes after surgical lower limb revascularization in England. Br J Surg 2011, 98(10):1373-1382.

65. Jameson SS, Bottle A, Malviya A, Muller SD, Reed MR: The impact of national guidelines for the prophylaxis of venous thromboembolism on the complications of arthroplasty of the lower limb. J Bone Joint Surg (Br) 2010, 92(1):123-129.

66. National Prospective Tonsillectomy Audit: Impact of NICE guidance on rates of haemorrhage after tonsillectomy: an evaluation of guidance issued during an ongoing national tonsillectomy audit. Qual Saf Health Care 2008, 17(4):264-268

67. Judge A, Evans S, Gunnell DJ, Albertsen PC, Verne J, Martin RM: Patient outcomes and length of hospital stay after radical prostatectomy for prostate cancer: analysis of hospital episodes statistics for England. BJU Int 2007, 100(5):1040-1049.

68. Mamidanna R, Bottle A, Aylin P, Faiz O, Hanna GB: Short-term outcomes following open versus minimally invasive esophagectomy for cancer in England: a population-based national study. Ann Surg 2012, 255(2):197-203.

69. Mamidanna R, Burns EM, Bottle A, Aylin P, Stonell C, Hanna GB, Faiz O: Reduced risk of medical morbidity and mortality in patients selected for laparoscopic colorectal resection in England: a population-based study. Arch Surg 2012, 147(3):219-227.

70. Mamidanna R, Eid-Arimoku L, Almoudaris AM, Burns EM, Bottle A, Aylin P, Faiz O: Poor 1-year survival in elderly patients undergoing nonelective colorectal resection. Dis Colon Rectum 2012, 55(7):788-796.

71. Smith AJ, Dieppe P, Porter M, Blom AW: Risk of cancer in first seven years after metal-on-metal hip replacement compared with other bearings and general population: linkage study between the National Joint Registry of England and Wales and hospital episode statistics. BMJ 2012, 344:e2383.

72. Aylin P, Tanna S, Bottle A, Jarman B: Dr Foster's case notes: How often are adverse events reported in English hospital statistics? BMJ 2004, 329(7462)

73. Quan H, Moskal L, Forster AJ, Brien S, Walker R, Romano PS, Sundararajan V, Burnand B, Henriksson G, Steinum O, Drosler S, Pincus HA, Ghali WA: International variation in the definition of 'main condition' in ICD-coded health data. Int J Qual Health Care 2014, July [Epub ahead of print].

74. Audit commission: Right data, right payment. Annual report on the Payment by Results data assurance programme 2011/12. 2012. http://www.audit-commission.gov.uk/2012/08/right-data-right-payment/.

75. Ghali WA, Pincus HA, Southern DA, Brien SE, Romano PS, Burnand B, Drösler SE, Sundararajan V, Moskal L, Forster AJ, Gurevich Y, Quan H, Colin C, Munier WB, Harrison J, Spaeth-Rublee B, Kostanjsek N, Ustün TB: ICD-11 for quality and safety: overview of the WHO quality and safety topic advisory group. Int J Qual Health Care 2013, 25(6):621-625.

76. Drössler SA, Romano PS, Sundararajan V, Burnand B, Colin C, Pincus H, Ghali W, World Health Organization Quality and Safety Topic Advisory Group: How many diagnosis fields are needed to capture safety events in administrative data? Findings and recommendations from the WHO ICD-11 Topic Advisory Group on Quality and Safety. Int J Qual Health Care 2014, 26(1):16-25.

doi:10.1186/1471-2288-14-126

Cite this article as: Keltie et al:: Identifying complications of interventional procedures from UK routine healthcare databases: a systematic search for methods using clinical codes. BMC Medical Research Methodology 2014 14:126.

\section{Submit your next manuscript to BioMed Central and take full advantage of:}

- Convenient online submission

- Thorough peer review

- No space constraints or color figure charges

- Immediate publication on acceptance

- Inclusion in PubMed, CAS, Scopus and Google Scholar

- Research which is freely available for redistribution 